\title{
The Isolation and Characterization of Bacteriophages from Listeria monocytogenes
}

\author{
By C. P. SWORD* AND M. J. PICKETT \\ Department of Bacteriology, University of California, Los Angeles, \\ California, U.S.A.
}

(Received 21 November 1960)

SUMMARY

The bacteriophages of Listeria monocytogenes have been studied with respect to isolation techniques and their use as diagnostic tools and as aids in epidemiological investigations. The occurrence of lysogeny was investigated in 123 strains isolated from human and animal sources throughout the world. Conventional procedures for isolation of phage were unreliable with Listeria since lysogenic strains did not always, by spontaneous lysis, release a detectable amount of phage. However, after exposure to ultraviolet radiation, such strains were induced to produce up to $10^{7}$ plaque-forming particles $/ \mathrm{ml}$. Some strains which did not release phage produced substances after irradiation possibly analogous to colicines. The lytic spectrum of 11 phages against 149 strains of Listeria was studied and a system of classification, with five of these phages, was used to place 127 of these strains in 8 phage types. Nearly all of the untypable strains were rough, undergoing dissociation, or were lysogenic. Phage susceptibility appeared to be closely associated with the serological type of the strain, but showed no relation to the animal source or the geographical origin. These studies indicated that Listeria phages could be used as a means of generic identification and also as a substitute for or an adjunct to serological typing in epidemiological investigations.

\section{INTRODUCTION}

The increasing frequency of reports of human and animal listeriosis tend to give this disease a measure of importance not formerly accorded it (Seeliger, 1958; Gray, 1959; Welshimer \& Winglewish, 1959). However, the epidemiological picture of listeriosis is incomplete, and neither biochemical nor serological procedures have been completely satisfactory in clarifying this picture. The successful application of bacteriophage typing to other bacterial genera suggests that such a method might be of value in tracing outbreaks of listeriosis or in proving transmission of the organism. Moreover, identification and differentiation of Listeria from other genera of Gram-positive rods still presents a problem in many laboratories. All too frequently, cultures of Listeria are erroneously identified as diphtheroids. Serological procedures for the identification of Listeria are expensive and are not readily adapted to most small laboratories. Bacteriophage filtrates, on the other hand, are

* Present address: Department of Bacteriology, University of Kansas, Lawrence, Kansas, U.S.A. 
inexpensive, easily prepared, relatively stable, and can be used by many laboratories not able to maintain a complete stock of reagents and typing sera for diagnosis of the less frequently encountered bacterial pathogens. Therefore, an evaluation of specific phage as an aid to the identification of genus Listeria seemed warranted.

Bacteriophage typing was first established as a practical and precise means of demonstrating subtle strain differences by Craigie \& Yen (1938) in their classic studies on Salmonella typhosa. The use of adapted phage permitted them to detect differences among strains of Vi-positive $S$. typhosa which were undetectable by biochemical and serological means. This method found wide acceptance in tracing typhoid outbreaks and has since been applied to other groups of bacteria including S. paratyphi B (Felix \& Callow, 1951), Shigella sonnei (Hammarström, 1949), and Pseudomonas pyocyanea (Warner, 1950). In addition, sensitivity to phage has been found to be a reliable method of identifying members of the genus Salmonella (Cherry, Davis, Edwards \& Hogan, 1954; Chi, 1956; Pickett \& Laughner, 1960), Malleomyces (Smith \& Cherry, 1957), and for differentiating Pasteurella pestis from $\boldsymbol{P}$. pseudotuberculosis (Gunnison, Larson \& Lazarus, 1951). Phage typing of Staphylococcus aureus, originally developed by Fisk $(1942 a, b)$, and later modified by others (Wilson \& Atkinson, 1945; Williams \& Rippon, 1952; Hood, 1953; Blair \& Carr, 1953,1960 ), is now extensively used in epidemiological investigations. Listeria monocytogenes phage was described by Schultz (1945) but, except for a preliminary report (Sword \& Pickett, 1958), phage typing of this species has not previously been reported.

To establish the reliability of a phage typing scheme, we first evaluated both the extra- and intrageneric specificity of Listeria phages. The former was pertinent in view of reported serological relationships between Listeria and both Staphylococcus aureus (Drew, 1946; Seeliger \& Sulzbacher, 1956) and enterococci (Seeliger, 1955 a). Also, phage pools were examined for evidence of interference among heterologous phages; the activity of undiluted stock phages and preparations diluted to routine test doses (RTD; as defined by Williams \& Rippon, 1952) were compared; and the relationship between colonial dissociation of the host and its susceptibility to phage was studied.

\section{METHODS}

Test strains and their routine culture. The 149 strains of Listeria used in this work were from human and animal sources throughout the world. They were obtained from at least twelve animal species through the courtesy of workers in ten different countries. The identity of all strains was confirmed by observation of motility in semi-solid agar as well as microscopic and colonial morphology. All cultures were maintained on Tryptose agar (Difco), stored at $4^{\circ}$, and transferred at 6-month intervals. Blood agar base (Difco) and heart infusion broth (Difco) were used for propagating phages and for typing procedures.

Serological properties. In many cases information about the serotype was supplied by the source laboratory. However, to confirm this and to identify untyped cultures the procedures for immunization, agglutinin-absorption, and typing as described by Paterson $(1939,1940)$ and Seeliger $(1955 b)$ were used. The following strains from the National Collection of Type Cultures (London, England) were used as antigens: 2167, 5105, 5214 and 5348. 
Isolation of bacteriophage. Cultures of certain strains (44-24 $\mathrm{L}, 44-50,44-51$, and 44-67 L) which have been shown by the method of Fisk $(1942 a, b)$ to carry phage, did not always contain enough free phage particles to be readily detectable when spotted on indicator strains. Preliminary use of the ultraviolet induction technique of other workers (Liegeois-Muller \& Fredericq, 1952 $a, b$; Thibaut \& Fredericq, 1952) yielded promising results with these strains. A mineralight lamp (Model V41 Ultraviolet Products, Inc. San Gabriel, Calif., U.S.A.) which emitted approximately $52 \%$ ultraviolet radiation with a wavelength of 2537 A was used. The lamp (with filter) at a distance of $45 \mathrm{~cm}$. from the object being irradiated was shown by a General Electric germicidal ultraviolet intensity meter to produce $685 \mathrm{ergs} / \mathrm{cm}^{2} / \mathrm{sec}$. Irradiation for 1-2 min. at a distance of $25 \mathrm{~cm}$., followed by incubation at $37^{\circ}$ for $90 \mathrm{~min}$. yielded maximal phage titres, often as high as $10^{7}$ plaque-forming particles/ $\mathrm{ml}$. Listeria strains to be irradiated were grown overnight at $37^{\circ}$. Small volumes (2-3 ml.) were spread in a thin layer over the surface of open Petri dishes and irradiated. The dishes were swirled periodically during irradiation to provide maximum exposure, and the procedure was carried out in semi-darkness to avoid photo-reactivation. After irradiation and incubation the strains were spotted at spaced intervals by Pasteur pipettes on plates seeded with indicator strains. The indicator strains were included in a thin layer of semi-solid agar on the surface of blood agar base plates as described by Adams (1950). The spots were allowed to dry and the plates incubated at $37^{\circ}$. In this manner, each strain could serve in turn as the substrate on which the others were spotted and all desired combinations of strains could be achieved. A group of $\mathbf{1 2 3}$ strains was tested for the presence of phage by spotting on 52 strains chosen to include those of as many geographic, host and serological groups as possible.

Purification and preparation of stock phage suspensions. Spotted areas which showed the presence of plaques or confluent lysis were selected for further study. A small amount of the semisolid agar from such areas was removed by a wire loop and shaken in $1 \mathrm{ml}$. broth to elute the phage; $0.1 \mathrm{ml}$. of this broth was then incorporated into semi-solid agar overlays along with the appropriate seed organism. In this manner newly isolated phages were transferred two to three times from single plaques to insure purity of the final phage preparation. Stock phage preparations were obtained by harvesting from agar overlay plates by a modification of the method of Swanstrom \& Adams (1951). Phage suspension was incorporated into seeded agar overlay on blood agar base plates. After incubation the agar overlay was scraped from the surface of the agar base and suspended in heart infusion broth. Phage was recovered from the agar by elution overnight at $4^{\circ}$ followed by centrifugation at $2000 \mathrm{~g}$ for $30 \mathrm{~min}$. The resultant supernatant fluid was sterilized by adding $0.001 \%(w / v)$ thymol or by passage through a millipore HA filter pad (Millipore Filter Corp., Bedford, Mass., U.S.A.) and stored at $4^{\circ}$. Titres of phage suspensions ranged from $10^{8}$ to $10^{11}$ plaque-forming particles $/ \mathrm{ml}$. Preparations were stable at $4^{\circ}$ for at least 6 months and often for as long as 1 year.

Electron microscopy. Phage particles were concentrated from stock preparations by centrifugation at $15,000 \mathrm{~g}$ for $1 \mathrm{hr}$. in a Spinco (Model L) ultracentrifuge. The deposits were resuspended to one-tenth the original volume with broth and centrifuged at $2000 \mathrm{~g}$ for $1 \mathrm{hr}$. to remove large particles. High speed centrifugation was then repeated on the supernatant fluid, and the final pellet suspended in $1 \mathrm{ml}$. of 
neutral isotonic ammonium benzoate $(1 \cdot 8 \%, \mathrm{w} / \mathrm{v})$. This suspension was spotted on electron microscope specimen screens covered by a collodion membrane (Wyckoff, 1949). All screens were air dried, shadowed with palladium and examined with an RCA EMU electron microscope. Four phages $(82,135,51 \mathrm{~L}, 137)$ were examined by this method.

Routine procedure for phage typing. Agar overlay plates seeded with the bacterial host were prepared as described and spotted with phage suspensions by means of capillary pipettes. As many as twenty spots could be applied but ordinarily only a set of 4 phage preparations was used (a pool of phages 83, 135, 51 L, 24 L, 87). Since comparison of the lytic spectra of undiluted phage and phage diluted to the routine test dose revealed no differences, the former was used for typing.

\section{RESULTS \\ Isolation of bacteriophage}

Forty-three of the irradiated and spotted cultures lysed one or more of the $\mathbf{5 2}$ indicator strains of Listeria. Purified phage suspensions were obtained from 12 of these 43 by transfer from single plaques. No phage was isolated from strains of serotype 3 even after cross-testing a group of 10 such strains.

\section{Demonstration of bacteriocines after irradiation}

Thirty-one of the 43 previously mentioned lytic combinations failed to yield single plaques or phage when tested further. However, the lytic or inhibitory effect had a definite host range against the indicators. This effect was dependent on ultraviolet irradiation; unirradiated cultures did not cause lysis or inhibition of growth when spotted on indicators. This phenomenon was not further examined, but appeared to be referable to colicine-like agents. Such substances have been found in several bacterial species other than Escherichia coli, but have not been reported previously from Listeria monocytogenes. Jacob, Lwoff, Siminovitch \& Wollman (1953) suggested the term 'bacteriocine' for substances possessing the general properties of colicines.

\section{Electron microscopy}

Plate 1, fig. 1, shows the morphology of phage 83. No morphological differences were found among the 4 phages examined. The phage heads appear to be about $85-90 \mathrm{~m}$ in diameter while the tails measure $265 \times 15 \mathrm{~m} \mu$. A terminal knob on the tail (not shown here) was present in some preparations, but was never as pronounced as with some phages.

\section{Effect of Listeria phages on heterologous species}

To establish generic specificity undiluted stock phages $83,135,51 \mathrm{~L}, 24 \mathrm{~L}$ and 87 were spotted on the following heterologous bacterial species: Corynebacterium pyogenes, C. pseudodiphtheriticum, C. pseudotuberculosis, Erysipelothrix rhusiopathiae, Lactobacillus arabinosus, L. brevis, L. buchneri, L. casei, L. fermenti, L. lycopersici, Staphylococcus aureus, Streptococcus equi, S. faecalis. In no instance was lysis observed. 


\section{Lytic spectrum of phages against strains of Listeria}

Eleven phage preparations (phages $23,24 \mathrm{~L}, 51 \mathrm{~L}, 61,71,83,87,113,132,135$, 137) were spotted on 149 strains of Listeria. The lytic spectrum of each preparation was usually restricted to strains of the serotype from which that phage had been obtained. Furthermore, there appeared to be two rather broad but distinct groups of strains with respect to phage susceptibility, namely, those lysed by one or more of the following phages: $23,24 \mathrm{~L}, 71,83,132,135$ and 137 , and those lysed by one or more of phages $51 \mathrm{~L}, 61$ and 113 . Since several of these phages possessed almost identical patterns of activity, only those with distinctly different spectra were used in developing a phage typing scheme. For this, a system of classification using only phages 83, 135, 51 L, 24L and 87 was devised (Table 1). Phages 83 and 135 were quite similar, having only minor differences in their ranges of activity. Therefore these two were mixed into a single pool. The spectrum of phage $51 \mathrm{~L}$ appeared to complement that of the pool $(83+135)$. By spotting this battery of four phage preparations on an unknown strain, the latter could be classified in one of the eight groups listed in Table 1 or else was insensitive to all five phages. Only 22 out of 149 strains $(14.7 \%)$ were not sensitive to bacteriophage. Of these untypable strains, 2 were lysogenic and hence immune to phages related to their lysogenizing phage, and 19 were, colonially, non-smooth or frankly rough.

\section{Table 1. Bacteriophage sensitivity patterns of Listeria strains}

\begin{tabular}{|c|c|c|c|c|}
\hline \multirow{2}{*}{$\begin{array}{l}\text { Phage } \\
\text { type }\end{array}$} & \multicolumn{4}{|c|}{ Reactions with typing phages } \\
\hline & $83 / 135$ & $51 \mathrm{~L}$ & $24 \mathrm{~L}$ & 87 \\
\hline 1 & + & + & + & - \\
\hline 2 & + & + & - & . \\
\hline 3 & + & - & + & . \\
\hline 4 & + & - & - & . \\
\hline $\mathbf{5}$ & - & + & + & . \\
\hline 6 & - & + & - & . \\
\hline 7 & - & - & + & . \\
\hline 8 & - & - & - & + \\
\hline Untypable & - & - & - & - \\
\hline
\end{tabular}

Polyvalent pooled phage suspensions for generic identification of Listeria

A polyvalent pool of phages 83, 135 and $51 \mathrm{~L}$ was spotted on the group of 149 strains mentioned above. The results obtained with the pool expressed the cumulative effect of the individual phage spectra on all strains tested and suggested that the phages could be usefully employed for identification of the genus Listeria.

\section{Host and geographic distribution of phage types}

An attempt was made to determine whether phage sensitivity showed any relation to the animal host or to the geographic origin of the strain (Tables 2, 3). None was found. Thus it appears that phage type, like the serological types described by Paterson $(1939,1940)$, is independent of source. However, certain patterns were noticeable within limited groups of strains. We found that two strains (44-17, 44-18) 
isolated by Line \& Cherry (1952) from infants in the same hospital ward had identical patterns of phage sensitivity. These workers suggested transmission from one mother to the other since the mothers shared a bathroom. We also found that 5 out of 6 strains isolated by Roine, Raitio \& Vartiovaara (1953) in Finland from an outbreak of listeriosis in guinea pigs showed similar patterns of phage sensitivity. Similar tendencies were noted with other strains. It may then be possible to use this phage typing system for epidemiological purposes.

Table 2. Bacteriophage type distribution of Listeria strains according to animal source

\begin{tabular}{|c|c|c|c|c|c|c|c|c|c|}
\hline \multirow{2}{*}{$\begin{array}{c}\text { Phage } \\
\text { type }\end{array}$} & \multicolumn{2}{|c|}{ Strains } & \multicolumn{7}{|c|}{ Animal source } \\
\hline & No. & $\%$ & Human & Bovine & Ovine & Avian & Rodent & Porcine & Unknown \\
\hline $\mathbf{1}$ & $\mathbf{3}$ & $2 \cdot 0$ & 1 & - & 2 & - & - & - & - \\
\hline 2 & 1 & $0 \cdot 7$ & - & - & - & 1 & . & - & - \\
\hline 3 & 49 & $32 \cdot 2$ & 6 & $\gamma$ & $\boldsymbol{9}$ & 9 & 8 & 2 & 8 \\
\hline 4 & 6 & $4 \cdot 0$ & $\mathbf{3}$ & . & $\mathbf{1}$ & . & $\mathbf{2}$ & - & . \\
\hline 5 & 5 & $\mathbf{3 \cdot 3}$ & . & $\mathbf{3}$ & 2 & . & . & - & - \\
\hline 6 & 53 & $\mathbf{3 5} \cdot \mathbf{5}$ & 8 & 10 & 22 & 4 & 6 & 1 & 2 \\
\hline 7 & 5 & $\mathbf{3} \cdot \mathbf{3}$ & 2 & 1 & - & - & $\mathbf{1}$ & 1 & - \\
\hline 8 & 5 & $\mathbf{3 \cdot 3}$ & $\mathbf{5}$ & - & - & - & - & - & - \\
\hline Untypable & 22 & $14 \cdot 7$ & 10 & 3 & 6 & 1 & . & $\mathbf{1}$ & 1 \\
\hline
\end{tabular}

Table 3. Bacteriophage type distribution of Listeria strains according to geographic source

\begin{tabular}{|c|c|c|c|c|}
\hline \multirow{2}{*}{$\begin{array}{c}\text { Phage } \\
\text { type }\end{array}$} & \multicolumn{4}{|c|}{ Geographic source } \\
\hline & N. America & Europe & Asia & Australia \\
\hline 1 & 2 & - & 1 & - \\
\hline 2 & - & 1 & . & . \\
\hline $\mathbf{3}$ & 28 & 20 & 1 & - \\
\hline 4 & $\mathbf{1}$ & 5 & . & . \\
\hline $\mathbf{5}$ & 1 & 3 & 1 & - \\
\hline 6 & 36 & 12 & 5 & - \\
\hline 7 & 2 & 2 & . & 1 \\
\hline 8 & 2 & $\mathbf{3}$ & - & - \\
\hline Untypable & 7 & 14 & $\mathbf{1}$ & . \\
\hline
\end{tabular}

Relationship of phage type to serological type

The phage type of 51 serologically typed strains was determined. The group of strains was selected to contain representative numbers of all the serotypes. There was almost perfect correlation between serotypes 1 and 2 and sensitivity to the pool of phages $83+135$. Serologically, only the flagellar antigen ' $D$ ' separates these two serotypes, and strains of serotype 2 are very rare. Strains of both serotypes 1 and 2 belong to phage types 3 and 4 . Most strains of serotype 3 are phage-resistant but those which are sensitive are lysed only by phage 87 and therefore belong to phage type 8 . The phage-resistant serotype 3 strains are all intermediate or rough colonial types. Nearly all strains of serotype 4 are lysed by phage $51 \mathrm{~L}$ and therefore belong to phage types 5 and 6 . Only one case of cross-activity between the pool of phages $83+135$ and phage $51 \mathrm{~L}$ was noted in this group. Hence it appears that there is good correlation between phage sensitivity and serological type. 


\section{DISCUSSION}

The ultraviolet irradiation procedure used in this study was effective in increasing the phage titre of susceptible lysogenic cultures. Carrier strains (Lwoff, 1953) and non-inducible lysogenic cultures should be unaffected by such a procedure. However, if these strains did produce phage it would be as readily detectable by this procedure as with conventional cross-testing procedures. All phages isolated in this study were from lysogenic strains since all responded to ultraviolet induction. Thus, all are 'temperate' rather than 'virulent' according to Lwoff's definition (Lwoff, 1953).

Examination of those strains which were not sensitive to the lytic action of phage disclosed that most of these were not smooth, frankly rough, or lysogenic. These differences in susceptibility suggest that if only freshly isolated smooth strains were used, the finding of apparently untypable strains should be considerably diminished.

The failure of these Listeria phages to lyse strains of bacteria of other genera confirms their generic specificity and indicates that they could, in a polyvalent pool, safely be used as a means of positive generic identification of fresh isolates. The high rate of host susceptibility and phage specificity, as well as the relative ease and economy of procedure as compared with serological methods suggest that this group of phages can profitably be used either as a substitute for serological typing or as an adjunct to it in epidemiological investigations of listeriosis.

We wish to thank the many laboratories throughout the world who generously contributed cultures for this study. The authors are also indebted to Mr H. Froula and Mr E. Boller, Department of Engineering, University of California, Los Angeles, U.S.A., for their generous aid with the electron micrographs.

\section{REFERENCES}

Adams, M. H. (1950). Methods of study of bacterial viruses. Meth. med. Res. 2, 1.

Brair, J. E. \& CARR, M. (1953). The bacteriophage typing of staphylococci. J. infect. Dis. 93, 1.

BlaIr, J. E. \& CARr, M. (1960). The techniques and interpretation of phage typing of staphylococci. J. Lab. clin. Med. 55, 662.

Cherry, W. B., Davis, B. R., Edwards, P. R. \& Hogan, R. B. (1954). A simple procedure for the identification of the genus Salmonella by means of a specific bacteriophage. $J$. Lab. clin. Med. 44, 51.

CHI, L. (1956). Salmonella generic typing. M.A. thesis, University of California, Los Angeles, U.S.A.

Craigie, J. \& Yen, C. H. (1938). The demonstration of types of B. typhosus by means of preparations of type II Vi-phage. Canad. J. publ. Hlth. 29, 448.

Drew, R. M. (1946). Occurrence of two immunological groups within the genus Listeria. Studies based on precipitin reactions. Proc. Soc. exp. Biol., N.Y. 61, 30.

Felix, A. \& Callow, B. R. (1951). Paratyphoid-B Vi-phage typing. Lancet, ii, 261, 10.

Fisk, R. T. (1942a). Studies on staphylococci. I. Occurrence of bacteriophage carriers amongst strains of Staphylococcus aureus. J. infect. Dis. 71, 153.

Fisk, R. T. (1942b). Studies on staphylococci. II. Identification of Staphylococcus aureus by means of bacteriophage. J. infect. Dis. 71, 161.

Gray, M. L. (1959). Listeriosis. Arch. Pediatrics, 76, 488.

Gunnison, J. B., Larson, A. \& Lazarus, A. S. (1951). Rapid differentiation between Pasteurella pestis and Pasteurella pseudotuberculosis by action of bacteriophage. J. infect. Dis. 88, 254. 
Hammarström, E. (1949). Acta med. scand. 133, Suppl. 223. Cited by Boyd, J. S. K. (1952). Bacteriophage-typing and epidemiological problems. Brit. med. J. ii, 679.

Hood, A. M. (1953). Phage typing of Staphylococcus aureus. J. Hyg., Camb. 51, 1.

Jacob, F., Lwoff, A., Siminovitch, L. \& Wollman, E. (1953). Definition de quelques termes relatifs a la lysogènie. Ann. inst. Pasteur, 84, 222.

Liegeois-Muller, A. \& FredericQ, P. (1952a). Libération de bactériophage par des lysogènes de $S$. schottmuelleri sous l'effet des rayons ultraviolets. C.R. soc. Biol., Paris, $146,1630$.

Liegeois-Muller, A. \& FredericQ, P. (1952b). Recherches sur la libération de bactériophage par des Staphylocoques lysogènes après irradiation ultraviolette. C.R. soc. Biol., Paris, 146, 1404.

Line, F. G. \& Cherry, W. B. (1952). Meningitis due to Listeria monocytogenes. A report of two cases. J. Amer. med. Ass. 148, 366.

Lwoff, A. (1953). Lysogeny. Bact. Rev. 17, 269.

Paterson, J. S. (1939). Flagellar antigens of organisms of the genus Listerella. J. Path. Bact. 48, 25.

Paterson, J. S. (1940). The antigenic structure of organisms of the genus Listerella. J. Path. Bact. 51, 427.

Pickett, M. J. \& Laughner, S. M. (1960). Screening for Salmonella with bacteriophage. Amer. J. clin. Path. 33, 298.

Roine, P., Raitio, A. \& Vartiovaara, U. (1953). Listeria infections in the guinea pig caused by feeding with aureomycin. Nature, Lond. 172, 767.

Schultz, E. W. (1945). Listerella infections; a review. Stanford med. Bull. 3, 135.

SeEliger, H. (1955a). Serologische Kreuzreaktionen zwischen Listeria monocytogenes und Enterokokken. Z. Hyg. Infektionskrankh. 141, 15.

SeEliger, H. (1955b). Listeriose. Beiträge zur Hygiene und Epidemiologie, Heft 8. Leipzig: J. A. Barth.

Seeuger, H. (1958). Listeriose. Beiträge zur Hygiene und Epidemiologie, Heft 8. Leipzig: J. A. Barth.

Seeliger, H. \& Sulzbacher, F. (1956). Antigenic relationships between Listeria monocytogenes and Staphylococcus aureus. Canad. J. Microbiol. $2,220$.

Smith, P. B. \& Cherry, W. B. (1957). Identification of Malleomyces by specific bacteriophages. J. Bact. 74, 668 .

Swanstrom, M. \& Adams, M. H. (1951). Agar layer method for production of high titer phage stocks. Proc. Soc. exp. Biol., N.Y. 78, 375.

Sword, C. P. \& Pickett, M. J. (1958). Bacteriophage typing of Listeria monocytogenes. Bact. Proc. 38.

Thibaut, J. \& Frederica, P. (1952). Libération de bactériophage pas des souches lysogènes de $C$. diphtheriae sous l'effet des rayons ultraviolets. C.R. soc. Biol., Paris, 146, 1627.

Warner, P. (1950). The isolation of the bacteriophages of Ps. pyocyanea. Brit. J. exp. Path. 31, 112.

Welshimer, H. J. \& Winglewish, N. G. (1959). Listeriosis-Summary of seven cases of Listeria meningitis. J. Amer. med. Ass. 171, 1319.

Williams, R. E. O. \& Rippon, J. E. (1952). Bacteriophage typing of Staphylococcus aureus. J. Hyg., Camb. 50, 320.

Wilson, G. S. \& Atkinson, J. D. (1945). Typing of staphylococci by the bacteriophage method. Lancet, i, 647 .

Wyckoff, R. W. G. (1949). Electron Microscopy. New York: Interscience Publishers, Inc.

\section{EXPLANATION OF PLATE}

Fig. 1. Electron micrograph of $83: \times 65,000$. 


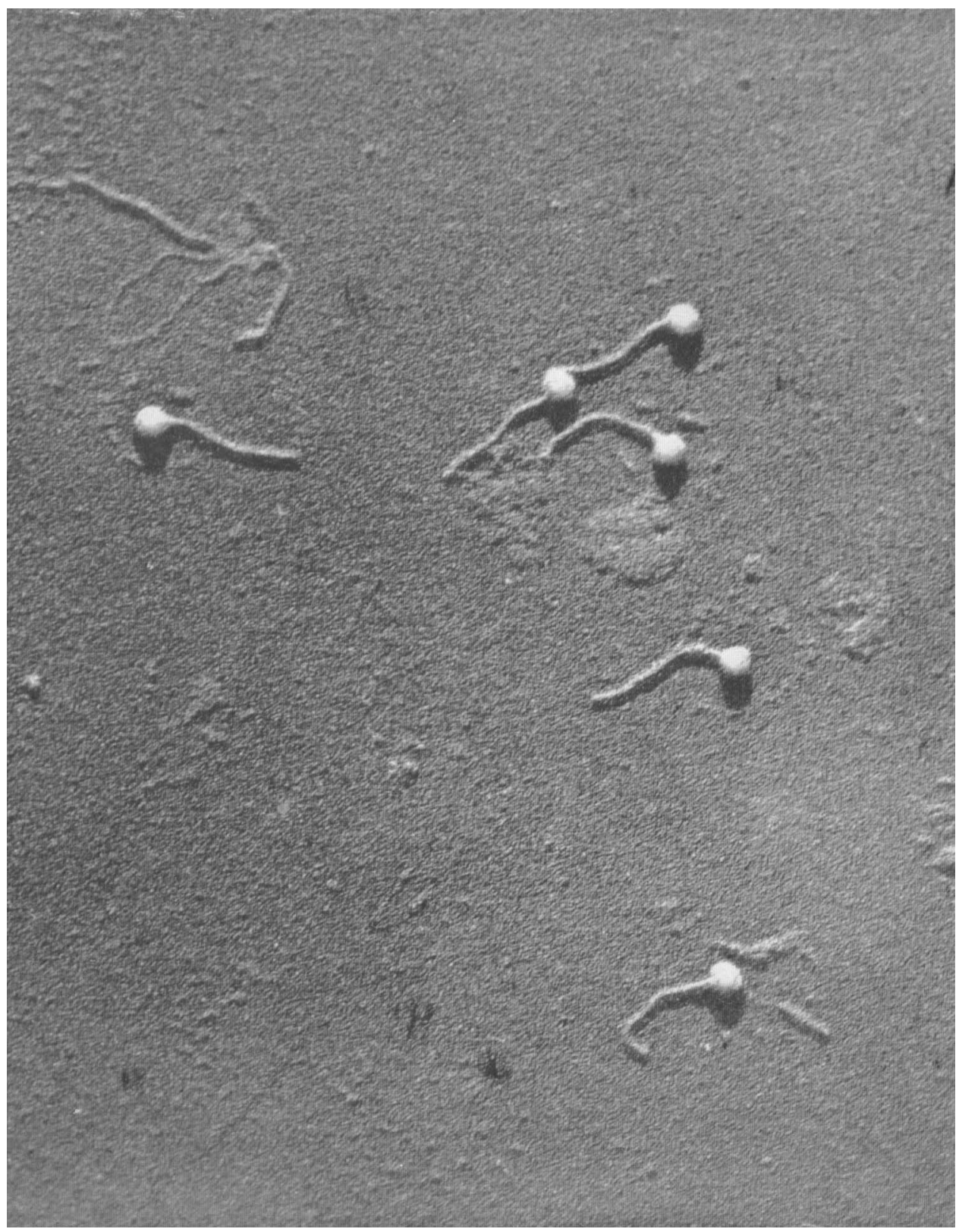

